\title{
El carácter maleable y proyectivo de la caricatura peruana durante el golpe de Estado. 1992
}

Recibido: 17/07/2020

Aprobado: 20/10/2020

\author{
CARLOS INFANTE YUPANQUI \\ Universidad Nacional San Cristóbal de Huamanga, Perú \\ carlos.infante@unsch.edu.pe \\ https://orcid.org/0000-0003-3920-5225 \\ RAFAEL GIOVANNY JORGE LEÓN \\ Universidad Nacional San Cristóbal de Huamanga, Perú \\ rafael.jorge@unsch.edu.pe \\ https://orcid.org/0000-0002-6714-4055
}

\section{RESUMEN}

El siguiente artículo presenta los resultados del estudio sobre el rol del humor gráfico en el Perú frente al golpe de Estado, en 1992. Examinamos un número importante de caricaturas a la luz del enfoque histórico, crítico y contextual. La idea fue seguir construyendo el derrotero de la caricatura peruana. Entre los resultados que encontramos fue que la caricatura ratifica su condición proyectiva y maleable. No ejerció un papel fundamental en la creación de las condiciones del golpe, pero, sin duda, sirvió a este objetivo. Fue un excelente vehículo para penetrar en los imaginarios sociales. Logró alcanzar su propósito al momento de afirmarse en el sentido común de la sociedad peruana, convirtiéndose en el magma de representaciones imaginarias, desde donde volvería a nutrir el humor con nuevos y viejos elementos simbólicos. En el estudio utilizamos un enfoque metodológico cualitativo; el análisis lo hicimos apoyándonos en el interaccionismo simbólico.

Palabras clave: Humor gráfico, golpe de Estado, Perú.

\section{The malleable and projective nature of Peruvian caricature during the 1992 coup d'état}

\begin{abstract}
The following article presents the results of the study on the role of graphic humor in Peru in the face of the 1992 coup d'état. We examined a significant number of caricatures from a historical, critical and contextual approach. The idea was continue following the path of Peruvian caricature. The results of the study showed that the caricature ratifies its projective and malleable condition. It did not play a key role in creating the conditions for the coup but it certainly served to that purpose. It was an excellent vehicle to penetrate the social imaginaries. It achieved its goal by asserting itself in the common sense of Peruvian society, becoming the magma of imaginary representations, from where it would nurture humor with new and old symbolic elements. In the study, we applied a qualitative methodological approach. The analysis followed the symbolic interactionism perspective.
\end{abstract}

Keywords: Graphic humor, coup d'etat, Peru 


\section{Introducción}

1 golpe de Estado o autogolpe impulsado por la administración del presidente Alberto Fujimori, con el apoyo de un grupo de oficiales de Jlas Fuerzas Armadas del país y de su asesor más cercano, Vladimiro Montesinos, representa uno de los momentos más emblemáticos de la historia política contemporánea en el Perú.

No fue el único golpe de Estado que se produjo durante el siglo XX; pero fue uno de los pocos procesos de ruptura constitucional aplicado contra un mismo gobierno, llamado también autogolpe. El caso más cercano se produjo en 1919, cuando Augusto B. Leguía hizo lo propio: cerró el Congreso y se erigió como dictador a pesar de haber ganado las elecciones abrumadoramente.

En 1990, Alberto Fujimori, un docente universitario e ingeniero de profesión, saltó a la arena política a competir por la Presidencia de la República y a enfrentarse a experimentados candidatos, algunos de ellos con mejor performance. Su presencia en el proceso electoral fue, al inicio, completamente insignificante. Sin embargo, en pocas semanas, contra todo pronóstico, la candidatura de Fujimori se elevó como la espuma y pasó a ubicarse en un lugar expectante en los sondeos de opinión, muy cerca de los tradicionales candidatos y del favorito de esas elecciones, el conocido novelista Mario Vargas Llosa, quien llegó a su límite en las encuestas, merced a cierta soberbia expresada en la millonaria campaña electoral y a la impresionante logística, que no cayó bien en un momento de profunda crisis económica.

La misma suerte corrió Alva Castro, candidato oficialista que arrastraba el desprestigio provocado por la pésima administración aprista que acababa de fenecer. Los dos candidatos de la izquierda legal, Henry Pease y Alfonso Barrantes, gozaban de un apoyo austero y compartían el desprestigio derivado de una crisis de los partidos políticos tradicionales (Tanaka 1998, Gonzales 2011, Adrianzén, 2011).

El inesperado ascenso de la candidatura de Fujimori no se explicaba solo por el desgaste de Vargas Llosa, su principal oponente, o de la crisis de los partidos políticos; existían razones de orden estructural que provocaron una crisis generalizada en la sociedad peruana, cuyas manifestaciones se reflejaron, en el terreno económico, con una hiperinflación que alcanzó a 2773\% y, en el político, con el avance de la insurgencia senderista (Palmer 1992, Infante 2007, Burt 2011), una crisis que puso a la nación frente a la eventualidad de un quiebre político y social, que no llegó a concretarse. En su lugar, 
se impuso el reequilibrio a través de reformas económicas de corte neoliberal (Infante 2010), que las aplicaría cualquiera de los postulantes que ganase las elecciones.

La victoria la obtuvo un outsider, quien aprovechó la ocasión para irrumpir con un discurso pragmático, con un liderazgo personalizado y que, aparentemente, no se veía comprometido con organización política y económica alguna. (Cotler y Grompone 2000, 85).

Esta serie de factores terminaron por catapultar a Fujimori a la Presidencia de la República, quien, tan pronto instaló su gobierno, aplicó severas medidas de ajuste, logrando estabilizar dramáticamente la economía del país. Un año más tarde, en noviembre de 1991, en la línea de lo establecido por el Consenso de Washington, su gobierno emitió un total de 126 decretos legislativos, 37 de ellos fueron en materia de pacificación (Infante 2007, 51; Burt 2011, 282). E1 paquete de normas sería el preludio de una decisión que buscaba concentrar todo el poder en manos del mandatario de la nación.

El 5 de abril de 1992, en un mensaje inesperado para el país, Alberto Fujimori anunció la disolución del Parlamento nacional. Una columna de tanques y decenas de efectivos militares, cerraron el acceso a la sede del legislativo y a entidades públicas. Al cierre del Congreso, le sobrevino la censura de los medios de comunicación, el cese de "los miembros de los tribunales judiciales y del servicio diplomático, intervino las universidades públicas y persiguió a dirigentes políticos" (Cotler y Grompone 2000, 30).

Esa mañana, los medios de comunicación, especialmente la prensa, dejaron en blanco ciertas partes de sus portadas y de sus páginas interiores, en señal de la censura oficial. Pero, la alianza entre el régimen fujimorista y la mayoría de medios legales de comunicación no tardaría mucho en restablecer y sellarse (Infante 2007), alineándose en torno a un solo discurso frente al principal problema del Estado peruano: la subversión. Así, se forjó una coalición perversa que eliminó por algún tiempo las diferencias políticas entre gobierno y opositores.

Asimismo, esta ruptura histórica dividió en dos momentos inequívocos el comportamiento de los medios de comunicación, en especial, el de la prensa, tanto en su línea editorial como en su discurso.

Antes del golpe de Estado, la oposición debió estructurar una línea de pensamiento, algo inconsistente, que debía arrastrar a elementos visuales como la caricatura. No obstante, el esfuerzo de este artefacto cultural por lograr una autonomía discursiva, que ya se venía construyendo desde hace un siglo, gra- 
cias a un proceso histórico por el que transitó el humor gráfico (Infante 2008, 2010), se alteró debido al sentido errático del discurso humorístico.

Sin mostrarnos interesados en un estudio comparativo entre el comportamiento de la prensa y el de la caricatura, examinamos una muestra de láminas con marcado cuidado, con el propósito de descubrir el rol de la caricatura peruana, frente al golpe de Estado de 1992. De más está decir, por el conjunto de investigaciones sobre el tema, que emprendimos desde hace algo más de una década, que la producción periodística y la caricatura poseen lógicas distintas y caminos relativamente independientes. (Infante 2008a, 2008b, 2010, 2015, $2018,2020)$. Por lo pronto, exploramos la racionalidad del humor gráfico en otro periodo crucial de la historia política contemporánea, en el marco de la línea de investigación que está en proceso de construcción.

\section{Métodos y materiales}

En la investigación hicimos uso de una metodología de enfoque cualitativo. La metodología que desarrolla este estudio comprende, además, técnicas como el análisis contextual y, por momentos, la técnica de análisis simbólico, las que convergen en dos métodos, el interaccionismo simbólico y el método contextual o crítico.

Los datos están compuestos por las láminas que se publicaron en los periódicos de circulación nacional, durante el periodo que cubre los días previos y los días posteriores del autogolpe. Dichas láminas fueron seleccionadas en base a criterios de saturación; vale decir, en base a la densidad de información existente sobre el hecho social y a su cercanía a la fecha del golpe de Estado. Las fechas varían, ligeramente. No son cinco días antes, ni cinco días después. Este criterio mecánico no se ajusta a investigaciones que admiten variables con elementos inestables, tales como la regularidad de la publicación de la caricatura, el vínculo del caricaturista con el medio, su visión frente a la realidad social y política, su condición de columnista o de colaborador, es decir, los criterios no son uniformes. Una rápida revisión de los medios desde meses anteriores sirvió de mucho para encontrar láminas que ayudaron en un mejor análisis y en una adecuada comprensión de la realidad, tan inestable y compleja.

Es por esto que, seleccionamos un número heterogéneo de viñetas correspondientes a cada impreso. De un total de 175 imágenes (El Comercio, 
8 láminas entre marzo y abril de 1992; El Popular, 9, entre marzo y abril de 1992; Expreso, 17, entre marzo y abril de 1992; La República, 103, de mayo de 1991 a 1992; Ojo, 26, de marzo y abril de 1992; Caretas, 2, de marzo y abril de 1992), solo 35 caricaturas constituyeron una muestra representativa de rigor cualitativo.

\section{Resultados y discusión}

El golpe de Estado, conocido también como autogolpe, no parece haber sido planificado con mucha anticipación. Sin embargo, representó una decisión inevitable para los objetivos de una administración comprometida con lineamientos de política internacional, impulsadas desde la embajada norteamericana en Perú. Las empresas de comunicación, ciertamente, no participaron en la conspiración. No obstante, su auténtico rol, el de estructuras estructurantes (Bourdieu 1990), se evidenciaría con posterioridad, pues a parte de una actitud irreverente, registrada al día siguiente del pronunciamiento cívico militar, su rechazo a la racionalidad política del régimen se iría diluyendo y, el acostumbramiento o normalización, volverían a imponerse. La caricatura experimentó un momento de desequilibrio. Su papel subsidiario de la acción informativa se contuvo, especialmente, en el humor de la prensa crítica.

Alfredo Marcos es uno de los caricaturistas que más actividad registró en este periodo. Su innegable y confesa cercanía al régimen alanista, antes que aprista, fue crucial en esta etapa. No tuvo que exponer el estado de victimización del ex mandatario Alan García, para subvertir la lógica discursiva oficial. Explotó, más bien, la sensación generalizada de incertidumbre que reflejó el proceso de penetración del nuevo modelo económico de corte neoliberal, que comenzaba a asentarse en la economía peruana. Esa mezcla de desconfianza, miedo e incertidumbre, derivada de la realidad objetiva que se expresó en el estado de millones de peruanos, sumergidos en una pobreza extrema, como efecto de un periodo de crisis jamás visto en la historia social peruana, sirvió de insumo para la viñeta de Alfredo.

El corte social de la caricatura no afectó el espíritu de las láminas de Alfredo. La coyuntura o, más bien, la realidad social condujo a cerrar el círculo del humor, alrededor de la economía. El material era vasto. La realidad política pasó a un segundo plano. 
La página de opinión del diario Ojo, hacia marzo de 1991, se avocó también a enfocar el tema económico. Pero, las razones no giraban alrededor de la reducción de la inflación, en el contexto de las medidas económicas restrictivas (Gonzales 1999, 317) o, llamado también, ajuste estructural de la economía (Castillo 2011, 866) sino, ambiciosamente apuntaba al programa económico, el mismo que se encontraba sustentado en las reformas liberales que comenzarían a implementarse ese año, luego de su aprobación, mediante un paquete de decretos publicado en setiembre de 1991.

El programa económico sería, simplemente, para la caricatura, un globo de ensayo, algo inestable y predeciblemente vulnerable.

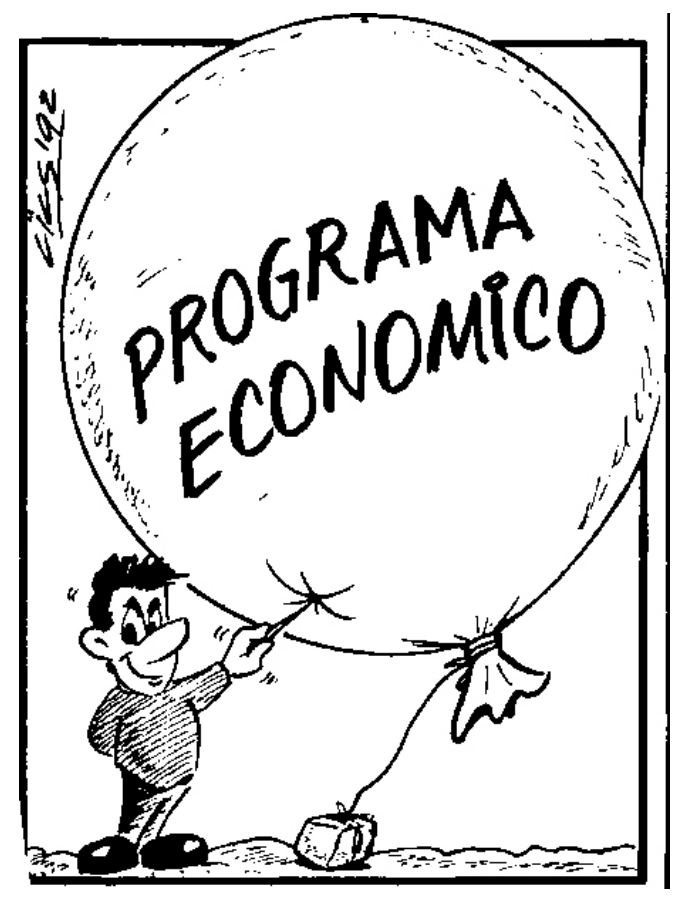

Figura 1. Lámina del diario Ojo, 1 de marzo de 1992

La ausencia del personaje objeto es algo que llama la atención en la lámina de Ojo. La eficacia de la caricatura se pone en riesgo, aunque el espíritu se mantiene. El humor emplea la metáfora del globo, cuya forma esférica pretende una totalidad jurídica del poder absoluto, pues "designa el territorio limitado sobre el que se ejerce el poder de un personaje" (Chevalier 1986, 553). Ese poder, cuanto más grande se muestra, parece ser más absoluto y 
totalizante, pero, al mismo tiempo, más vulnerable. Su poder se vuelve ficticio cuando el globo revienta. He ahí la ironía. El programa económico representa un poder absoluto, pero precario.

La economía no era el único problema que enfrentaba el país: la violencia política desatada 12 años antes, con la actuación de grupos subversivos, seguía causando graves daños a la estructura del Estado. Sin embargo, un problema de corte político pretendía ser reducido a un asunto netamente jurídico. Esta era la idea que se desprendía de la caricatura de Miguel Ángel Masías, el dibujante que colaboraba con Expreso desde la década anterior. La alegoría era simple. Un magistrado en ropa interior solo significaba una conducta timorata y reflejaba los miedos que cubrían las decisiones de los jueces a la hora de juzgar a los acusados por terrorismo.

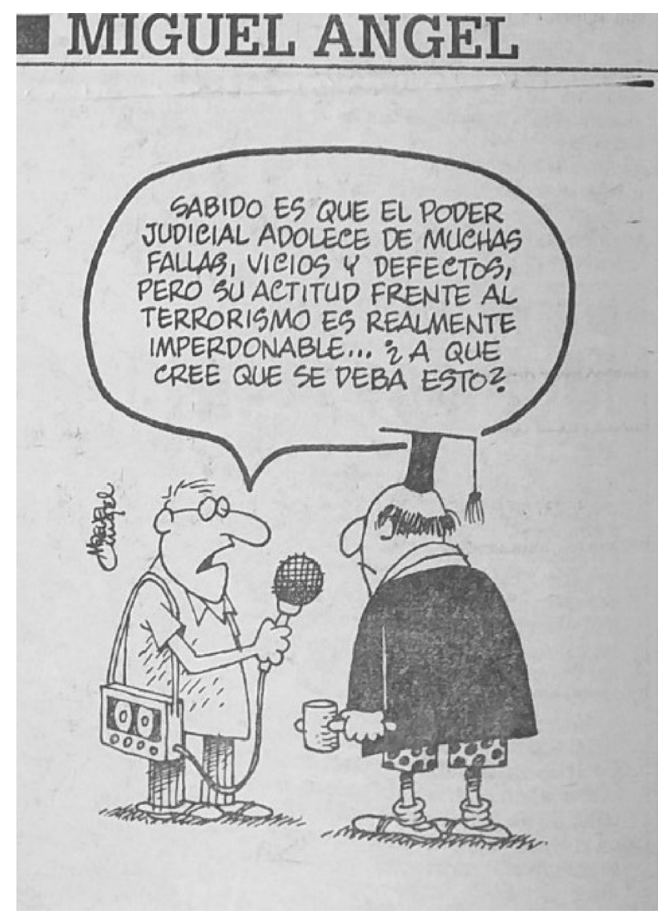

Figura 2. Lámina de Miguel Ángel. Diario Expreso, 2 de marzo de 1992

El impreso acusaba, indirectamente, al Poder Judicial de cierta complicidad y excesiva permisividad con el terrorismo.

En ese momento, pocos se imaginaban la intención real del régimen. Pero, el paquete de decretos emitidos meses antes, la agresiva cruzada mediática 
contra los partidos políticos y el Congreso peruano, la presión contra algunas entidades del Estado, vinculadas al control constitucional y el directo ataque al Poder Judicial, ya rebelaba una estrategia en proceso, que pretendía justificar medidas administrativas en el marco del pragmatismo del régimen.

Del Poder Judicial se decía, por ejemplo, que a falta de pruebas solía liberar a los terroristas capturados, algo que se interpretaba como un acto de cobardía y de infamia. Dos meses después, el 5 de mayo de 1992, aquel mismo sistema de justicia, "frágil" y "pusilánime", cambiaría radicalmente de imagen. Ese día, el Ejecutivo aprobaría el Decreto Ley N. ${ }^{\circ} 25475$, con el cual se creó un sistema de justicia secreto que dio vida a los llamados jueces "sin rostro". Su justicia amparada en el anonimato sería implacable.

He ahí el espíritu de la caricatura. Consciente o no de ello, Miguel Ángel Masías, desnudaba la debilidad del sistema judicial y de sus principales operadores, los jueces, entrando en sintonía con el discurso oficial.

En sus ediciones posteriores, Carlos Roose se ocuparía del tema económico. Alberto Fujimori fue el referente principal de la imagen de ese momento. Sus medidas económicas, de alcance histórico en la realidad social del país, no podían menos que ser objeto central de la caricatura. Fujimori era el responsable del más radical ajuste económico y estructural nunca antes experimentado en el Perú. Sin embargo, para aplicarlo, debía generar las condiciones necesarias orientadas a debilitar a los actores sociales y deslegitimar a la oposición.

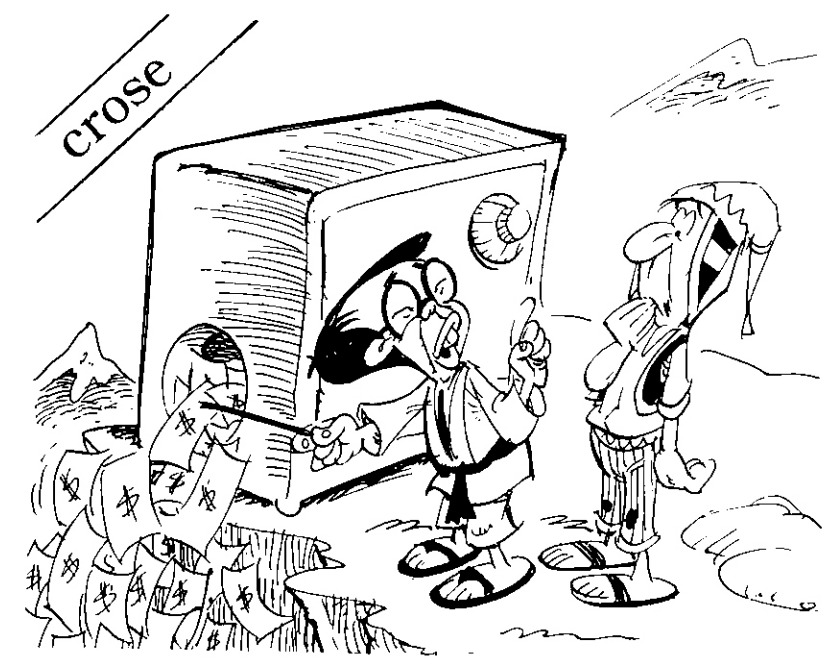

Figura 3. Lámina de Carlos Crose. Diario Ojo, 9 de marzo de 1992 
En este contexto, todo el aparato estatal y los medios de comunicación, afectos al régimen, se encargaron de actuar como fuerza de choque. La caricatura no podía actuar de modo distinto. Seguiría la línea de los impresos donde sus viñetas eran publicadas.

La caricatura desliza dos formas de discriminación. La primera, cuando le atribuye a Fujimori, cierta voluntad por subestimar la capacidad de comprensión de un sector importante del país y, la segunda, asignada a la propia caricatura que reproduce estos prejuicios.

Pero la relación entre Fujimori y los sectores más empobrecidos del país (v.g., la sociedad rural), siempre se caracterizó por formar parte de una estructura paternalista, discriminatoria y funcional. Si bien no llegó a los niveles que alcanzó la administración de Leguía durante el Oncenio, que impuso un "indigenismo oficial y una prédica revindicacionista de tipo paternalista y exotizante" (Villari y Menacho 2017, 133), pero tampoco construyó una lógica opuesta. Fujimori, al igual que Leguía, "pondría al descubierto las contradicciones de un mensaje indigenista retórico acompañado por una política de explotación" (Villari y Menacho 2017, 133).

Acaso la caricatura, sin desearlo, mostraría las miserias de esta relación. Pero, sería, una relación, como dijimos, funcional al interés del régimen. ${ }^{1}$ Fujimori precarizó aún más la realidad del campesinado, al privilegiar a sectores económicos de exportación asentados en la costa peruana. El modelo primario exportador resagó por completo a los habitantes de los Andes.

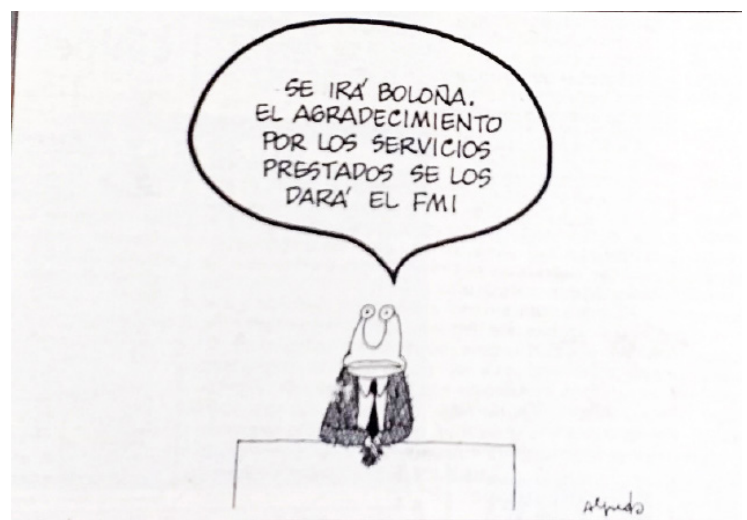

Figura 4. Lámina de Alfredo Marcos. Diario La República, 10 de marzo de 1992

1 Durante las elecciones de 1990, Cambio 90, el partido que acompañó a Fujimori en su carrera electoral, concentró un mensaje que resumía su interés por establecer una hibridación entre lo mestizo y lo popular (Ortiz de Zárate 2016). 
En la orilla contraria, La República, dirigida por Gustavo Mohome Llona, reconocido dirigente izquierdista, seguía en su objetivo de cuestionar la política económica implementada por los operadores del Fondo Monetario Internacional. Carlos Boloña, ministro de Economía y Finanzas, sería el blanco de la ironía.

Para un sector de la nación, Boloña y el régimen fujimorista habían introducido una política económica de contrabando, orientada a favorecer al gran capital nativo y extranjero, pero, sobre todo, a los organismos financieros internacionales. El titular de Economía y Finanzas sería el operador de este proceso en representación de un régimen que, a partir de entonces, comenzaría a pagar puntualmente la deuda contraída con el FMI, flexibilizaría las relaciones laborales y entregaría todos los recursos naturales que Estados Unidos quiso. (Lora Cam 2001, 105).

Mientras Alfredo Marcos seguía su propio camino, Crose no daba tregua al discurso antioficial.

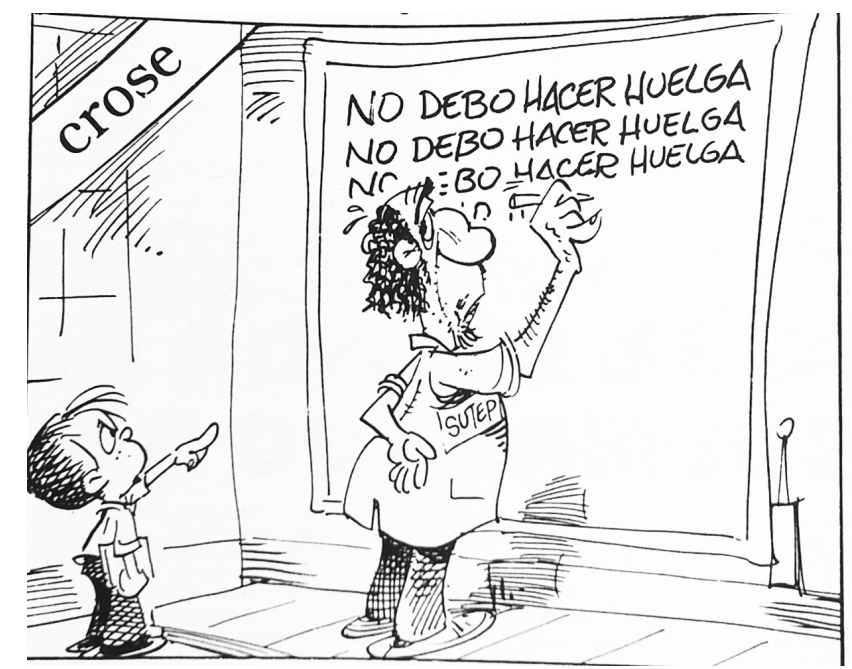

Figura 5. Lámina de Crose. Diario Ojo, 12 de marzo de 1992

La caricatura logró apoyarse en la metáfora e invirtió el sentido común. El maestro debía repudiar la huelga, tanto como el niño lo hacía con las malas artes. La pizarra, aquel muro que por momentos expiaba culpas, debía servir de mural para que el maestro hiciera lo propio.

Alejada de su esencia crítica, la huelga, según esta visión neoliberal, había pasado a ser la rémora del desarrollo o, más bien, del crecimiento económico, 
principal variable de la racionalidad pragmática. Ninguna reivindicación gremial o laboral seguiría teniendo legitimidad si la huelga sería el medio para reclamarla. La huelga, que por casi mil años se entendió como una herramienta de protesta, constituye un procedimiento racional, empleado por los trabajadores en contra de quienes ejercen control del proceso productivo; las miradas son dicotómicas en sectores en conflicto. Para el sector gremial, comprende un mecanismo que se activa a favor del reclamo ante la vulneración de ciertos derechos legitimados. Para la patronal, generalmente, constituye una metodología que subvierte el statu quo laboral, de ahí que siempre ha merecido una legislación prohibitiva y restrictiva. Los regímenes políticos, cuanto más duros y conservadores son, ven las huelgas como procedimientos sediciosos.

En los noventa, la ofensiva estatal contra la partidocracia y, especialmente, contra los partidos de izquierda, se extendió a toda organización social y popular. A ello debía sumarse, la acción represiva (y también de la insurgencia), que apuntó a ciertos dirigentes sociales llevando a generalizar una especie de miedo colectivo a la participación política ${ }^{2}$. Desde ambos flancos, la necesidad de agremiarse fue reemplazada por la oportunidad de sobrevivencia. Los sindicatos prácticamente fueron desmantelados. Los gremios mineros, fueron duramente reprimidos en los ochenta. Solo el Sindicato Único de Trabajadores en la Educación (SUTEP), controlado fundamentalmente por la facción de Patria Roja, un partido político extremista de los setenta, logró sobrevivir a la purga sindical. El SUTEP fue uno de los pocos gremios que se mantuvo activo en los noventa, pero, para nadie era extraño la influencia subversiva que había en su interior.

En caricaturas publicadas en otros medios, el imborrable recuerdo de la experiencia vivida durante el quinquenio pasado, despertó la efervescencia de una crítica que fue llevada al espacio del humor gráfico. El colosal fracaso de la administración aprista entre 1985 y 1990, sería la fuente inagotable de la imaginación humorística.

Para la caricatura de oposición, el epicentro de la política, aun con insumos coyunturales, era el régimen y sus políticas económico sociales. Para el humor oficial y oficioso, el objeto caricaturesco serían los opositores a la administración fujimorista. Para el humor de algunos medios que pretendían

2 Entre 1980 y 1989, alrededor de 23 dirigentes gremiales fueron asesinados en el conflicto armado interno. De este número, dos fueron asesinados por Sendero Luminoso. Entre 1990 y 1992, cuatro dirigentes sociales fueron asesinados, tres por fuerzas estatales y uno por Sendero. (CVR, t. III, 2004, 362-363). La cifra es muchísimo mayor en el caso de dirigentes encarcelados y de personas torturadas durante el momento de su detención. 
cierta neutralidad, la caricatura estaba concentrada en el gobierno saliente. En el caso de Alfredo Marcos, la línea estaba definida. Su objetivo sería la administración fujimorista, su plan económico y el sesgo autoritario que comenzaba a asomar.

A menos de un mes de producirse el golpe de Estado, Fujimori volvió a viajar a Japón, con la finalidad de concretar un apoyo financiero. Su entrevista con el emperador Akihito dio como resultado 100 millones de dólares en ayuda y donativos a favor del país. A esto alude Alfredo Marcos en su viñeta, al viaje que realizaba el mandatario con regular frecuencia.

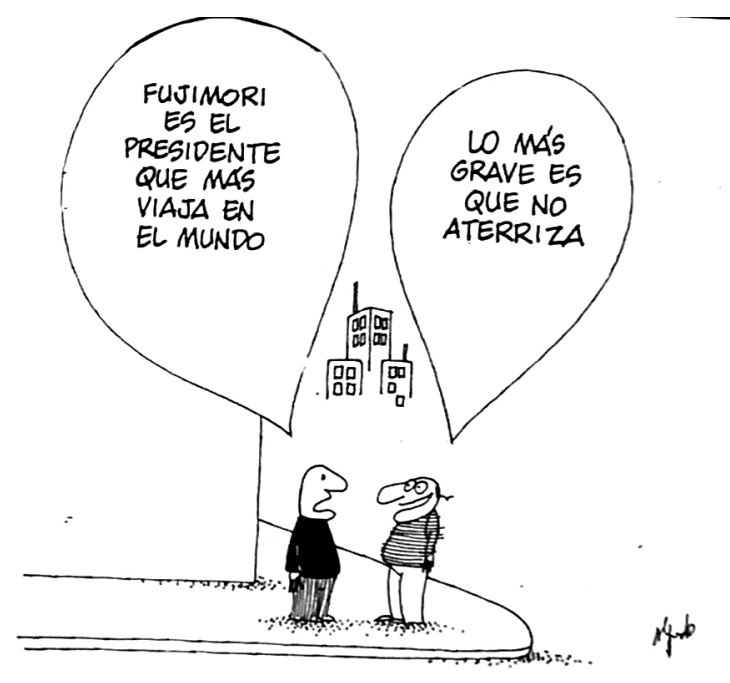

Figura 6. Lámina de Alfredo Marcos. Diario El Popular, 18 de marzo de 1992

El pragmatismo se caracteriza por descubrir los efectos prácticos e inmediatos del pensamiento. Fujimori postulaba esta doctrina. Sus políticas económicas y sociales "buscaban resultados positivos en el corto plazo, dada la presión social, sin tener en cuenta un horizonte más amplio" (Gonzales de Olarte y Samamé 1991, 39). Detrás de su retórica, teñida de una falsa conciencia (Infante 2010) y de una filosofía que impulsaba la defensa de un híbrido mestizo popular, encubría un pensamiento ultra conservador, algo que se evidenció en la aplicación de un programa económico totalmente ortodoxo (Gonzales de Olarte y Samamé 1991, 38). Fujimori debía saber que las medidas adoptadas no servirían a las grandes mayorías, cuyo estado de miseria se profundizó en los siguienes años, pero, sería su popularidad extraída de un 
hábil manejo de la cultura política de corte populista del electorado peruano, la que le sirvió para gozar de una aceptación social aparente.

Siendo este el caso, la realidad fue su peor aliada. Si en 1991, el número de pobres fue 12.6 millones ( $57.4 \%$, según el INEI) y de 5.9 millones de pobres extremos (26.8\%); diez años más tarde, en 2001, la población pobre había aumentado a 14.4 millones de personas y a 6.4 millones de pobres extremos (Ames, 31 de diciembre de 2017). Su pragmatismo estaba condenando a millones de peruanos a sufragar los costos de una política económica beneficiosa, principalmente, para la oligarquía y los conglomerados extranjeros. Aterrizar o, más bien, pisar tierra, expresión popular que se refiere a mirar la realidad, era lo que le faltaba.

Este intercambio de golpes de caricatura se volvió recurrente. No solo temporal, sino, espacialmente; el humor gráfico sucumbía ante la coyuntura. Si Alfredo Marcos abría una herida en el régimen, Crose la cerraba.

En la lámina precedente, el drama del conflicto armado interno terminaría despertando una ligera señal de buen humor. Vale decir, frente a la tragedia que sometía al país entero, un gesto de solidaridad aparecía desde las manos del gobierno, sosegando la angustia de las víctimas, pero no de todas las víctimas.

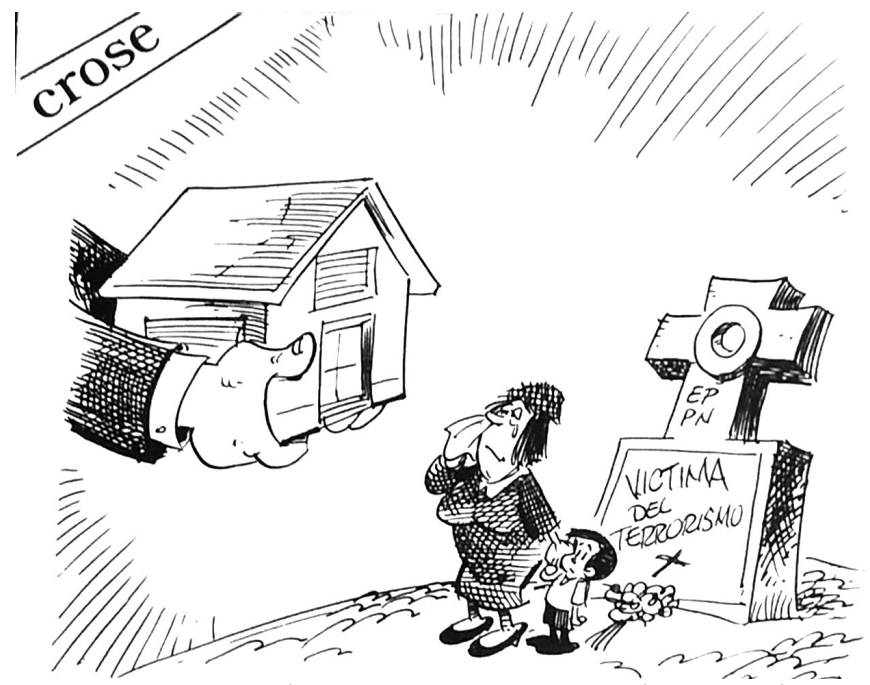

Figura 7. Lámina de Crose. Diario Ojo, 29 de marzo de 1992

Para el discurso oficial, las víctimas solo estaban en las filas de las fuerzas del orden y, circunstancialmente, entre los integrantes de las rondas campesi- 
nas. Es decir, eran víctimas, solo si habían perecido ante la acción sediciosa. En las filas de la subversión o entre quienes cargaban el estigma de una posible relación con Sendero Luminoso no habían víctimas. Los muertos siempre serían el resultado de la justicia estatal.

La viñeta describe aquel esfuerzo por compensar el acto de inmolación de sus hombres. En medio de la lámina de Crose, aparecen alegorías que sugieren interpretaciones desde el orden cósmico. La mano (salvadora) del Estado se presenta, cual si se tratara del divino y piadoso descenso del totem cristiano.

Las manos, símbolo de la potencia y de dominio (Chevalier 1986, 682), representan, también, la supremacía, pues, convierten el regalo (la casa) en un acto de justicia, en un mensaje de auxilio. No en vano, las manos que sostienen la casa aparecen en lo alto, iluminado por los rayos de una luz cuasi celestial.

Chevalier $(1986,684)$ al referirse a la mano de Dios, señala que esta se "representa a menudo saliendo de las nuves mientras el cuerpo permanece oculto en el cielo". Con el fin de manifestar su divinidad, las manos se rodean de destellos de luz. Esta alegoría simboliza algo concreto: "estar a su merced", dice Chevalier.

Curiosa casualidad, pero de eso se trata. La caricatura, una construcción cultural, se alimenta de toda forma de simbolismo, emplea alegorías y figuras que ordenan un cuasimundo imaginario, cuyo mensaje (más, si el humor es funcional) aparece empañado de cierta forma de humor. El gobierno, a la cabeza del Estado, salía a compensar el sacrificio de militares y policías, víctimas del terrorismo. El mensaje era claro, pero debía dosificarse empleando cierto simbolismo.

El humor no siempre calza con la realidad. A veces, va contra ella, como toda información. Pero, Alfredo Marcos, la usa instrumentalmente para erosionar el poder del régimen, denunciar el uso recurrente de los psicosociales y, de paso, cuestionar la política económica.

Lo social y lo político conviven en la realidad humorística. Generalmente, son el reflejo de una parte de la realidad material. Esto se desprende de una de las láminas de Alfredo Marcos, quien, conforme progresa la nueva racionalidad neoliberal, va descubriendo sus debilidades.

Si Crose o Alfredo Marcos se esforzaban por darle un soporte humorístico a la caricatura oficiosa, El Comercio no tardaría en darle sostenibilidad al discurso dominante. Su página editorial solía publicar una viñeta visiblemente 
ausente de humor, pero de mensaje concluyente. Eran los trazos menos inspiradores e imaginativos del humor gráfico de esos tiempos.

Bajo el título de Apunte del día, se editorializaba a través de un dibujo la posición del influyente periódico limeño. Caricaturizaba el ritmo de la actividad parlamentaria. En su imaginario, leyes que debían regular una serie de derechos sociales y políticos, se encontraban literalmente encarpetados. La ley de huelgas, por ejemplo, tan necesaria para liberalizar el control de estas medidas de fuerza desde la lógica liberal, aparecía con prioridad en la agenda pendiente.

En Expreso, en cambio, el ex mandatario aprista volvería, una y otra vez, a ser figura humorística. Sometido al descrédito absoluto, hacia principios de 1992, la imagen de Alan García solo serviría para establecer una dicotomía moral, social, política o de cualquier orden.

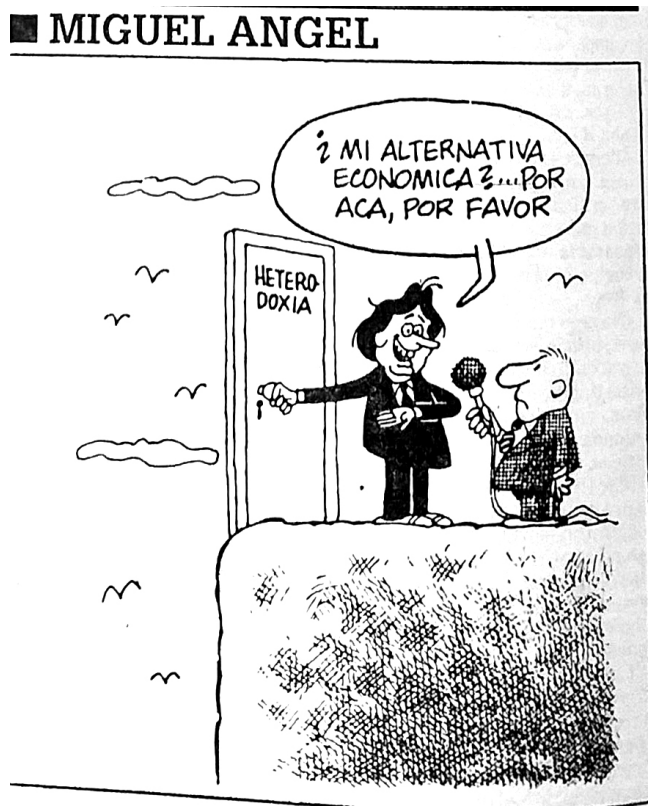

Figura 8. Lámina de Miguel Ángel. Diario Expreso, 5 de abril de 1992

Miguel Ángel organizaba el estigma. García solo representaría un modelo de pensamiento arcaico, inútil y apocalítptico. Su gobierno era el arquetipo perfecto de la anomia social. Pero la deliberada imagen que propuso la caricatura no pretendía confrontar otras formas de pensamiento económico, como la impulsada por el régimen fujimorista. Redujo —en la lógica del discurso 
oficial- el espíritu de la economía nacional a dos líneas: la ortodoxa y la heterodoxa. Esta última, personificada en García, solo reflejaría una regresión al pasado, un salto al vacío.

La economía heterodoxa, en donde confluían los pensamientos de evolucionistas e institucionalistas, la escuela de la regulación, los marxistas y radicales y los poskeynesianos, postulaba una forma de intervencionismo del Estado, con el objeto de erradicar las fallas del mercado, fallas que terminaron promoviendo el desenvolvimiento del monopolio; pero, también, la prioridad del Estado en fomentar la justicia social a través de políticas sociales, igualdad de condiciones para acceder a servicios públicos. (Zapata y Chávez 2017). El anuncio que García hizo durante su investidura como gobernante del Perú, de aplicar un modelo heterodoxo, resultó un fracaso, no por el espíritu que envolvía esa filosofía, sino por factores endógenos y exógenos.

Dualidad o no, la corriente ortodoxa, que a hurtadillas venía como colofón dentro del mensaje humorístico de Miguel Ángel, caminaba al mismo ritmo del modelo económico neoliberal. La ortodoxia económica, que logró prestigio a través de la llamada escuela de las "expectativas racionales" (Preston, en Kalmanovits 1998, 4), suponía un esquema menos flexible, respecto a la participación del Estado y del mercado, basado en los rigores de un positivismo económico, donde "los agentes económicos no son tan fácilmente manipulables como los supuestos por los intervencionistas" (Kalmanovits 1998, 4). El Estado debía reducir su papel a la mínima expresión, debía servir solo de ente regulador.

Miguel Ángel, al igual que el medio donde publicaba su viñeta, estaba claro en esto. Si Alan García había impuesto cierta política económica a despecho de la vida de millones de peruanos, para demostrar la inviabilidad del modelo heterodoxo, no cabía otro esquema que volver a la ortodoxia, una corriente conservadora que supone la aplicación desarrollada del capitalismo y de su esencia, el liberalismo económico.

Disuelta la duda frente a la eficacia de modelos económicos, la caricatura se aprestaba a sepultar el pasado empleando una de las figuras más sólidas del simbolismo universal: la puerta, cuyo significado también es escatológico. "La puerta como lugar de paso, particularmente de llegada, se convierte como es natural en el símbolo de la inminencia del acceso y de la posibilidad de acceso a una realidad superior" (Chevalier 1986, 856). Si esta es su significación, la puerta que pretende abrir el ex presidente García no puede menos 
que reflejar la entrada a un espacio de riesgo, de caos y fracaso. Si bien es un mundo conocido, la puerta aparece como el umbral de lo desconocido, como el tránsito entre la luz y las tinieblas.

El sarcasmo y la ironía son los recursos más fuertes en el humor gráfico de Miguel Ángel. Su eficacia es categórica, su resultado es rotundo. El imaginario se retroalimentará de esta construcción social. García y su gobierno pasarán a la historia como la administración más tóxica que conoció el país, ni su segundo gobierno que se condujo en medio de cierto equilibrio, gracias a factores exógenos, logró anular del pensamiento colectivo la imagen de cinco años de regresión y de crisis económica y política.

$\mathrm{Al}$ día siguiente del autogolpe fujimorista, Alfredo Marcos volvería a publicar una viñeta siguiendo su mirada crítica frente a la economía. Utilizando la metáfora de los tres mosqueteros, asignaba el papel de "tontos útiles" a quienes prestaban esmero por favorecer al interés del Fondo Monetario Internacional.

El caricaturista de La República no se detuvo en el acontecimiento de la víspera, un hecho que obligó a la prensa de circulación nacional a emitir páginas en blanco en sus portadas.

Lo mismo sucedió con Crose, su caricatura se mantuvo inmutable con respecto al autogolpe. Al día siguiente de la medida, que suspendió el estado de derecho y el orden constitucional, publicó una caricatura en contra de Javier Diez Canseco, el emblemático líder izquierdista, a quien el régimen fujimorista juzgaba de impenitente opositor. La figura del pistolero, de alguien que asesina a sangrefría, debía encarnar al hombre de filiación socialista.

La reacción frente al golpe, recién, se produjo dos días después. Alfredo Marcos lo hizo desde la caricatura de oposición, pero de una oposición conservadora, moderada y casi evasiva. Desarrolló un diálogo construido, asimétricamente, entre dos sectores sociales urbanos, cada cual con elementos marcadamente diferenciados, ya sea por sus atuendos o por el tipo de conciencia social que abrazaban.

La viñeta reproduce con exacta precisión la realidad capitalina de los noventa: asentamientos humanos instalados en los cerros de los conos, hogares alzados con esteras o material deleznable, en lomas de arena y con pobreza a discreción, sin agua, sin luz, sin servicios higiénicos, sin calidad de vida suficiente. Acaso, habitada por gente desempleada o subempleada, pero, con certeza, miembros de esa enorme comunidad de pobres y pobres extremos. 


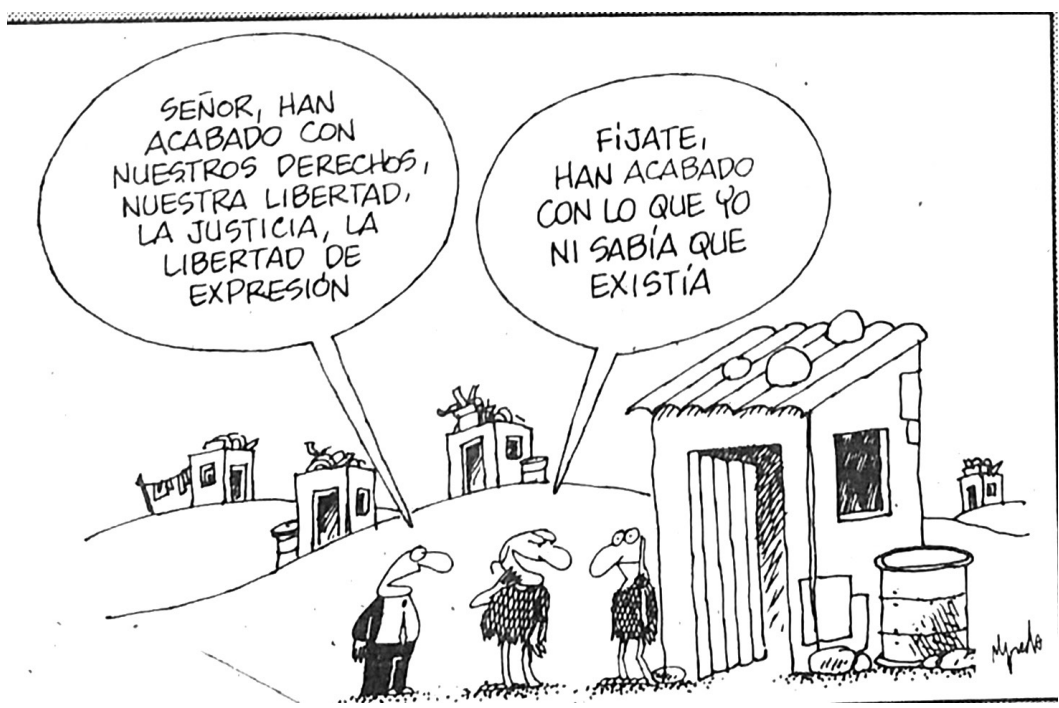

Figura 9. Lámina de Alfredo Marcos. Diario La República, 7 de abril de 1992

No hay duda, la viñeta era profunda. Condensaba los distintos imaginarios dominantes y la conciencia de cada segmento social. Ninguna era artificial, ni la de aquél que miraba el golpe de Estado como la reacción brutal de un sector dominante, sediento de poder; ni la de quienes se inclinan por una comprensible indiferencia frente a la unilateral medida. Sentían que, con la ruptura del orden constitucional o sin ella, su vida seguiría siendo la misma: tan miserable como excluyente.

\section{El sarcasmo fue providencial}

El poblador de un asentamiento humano, generalmente migrante, no es el "lumpen de extracción provinciana" (Bailón 2004, 55); es aquel que vive en una zona marginal, sin mayores derechos sociales que aquellos que él mismo conquista. Adolece de vivienda, de salud, de educación, vive a salto de mata esperando ser desalojado del pequeño predio que ha invadido. Generalmente, se sumerge en la cultura popular y construye una nueva vida, en una suerte de híbrido que combina hábitos exportados de sus lugares de origen, con las nuevas prácticas que descubre en la capital. Desarrolla una informalidad, que calza con sus posibilidades e intereses, con las cuales busca sortear los muchos obstáculos que tiene la vida en un espacio hostil, pero que ha comenzado 
a dominar. El golpe de Estado no le afecta, porque no usurpa derechos que aún no tiene, ni goza. No se favorece de la justicia, porque es ella quien la persigue; no disfruta de libertad individual, salvo aquella que se suministra a sí misma en medio de la anomia social. No reclama libertad de expresión, porque no goza de los privilegios de hacer uso de los medios de comunicación masiva. Su palabra no existe, su anonimato solo emerge de modo anecdótico y humorístico.

El Popular es otro medio de propiedad de la familia Mohme Llona. Fue creado para aquel sector que describimos en el párrafo anterior. Cappellini $(2005,33)$ lo considera un diario chicha, nacido a principios de los ochenta en el contexto del nuevo desborde popular, parafraseando a Matos Mar (1986). Sus viñetas, generalmente, de corte social, no perdieron la oportunidad de pronunciarse frente al autogolpe, desde la racionalidad del humor negro. La fuerza militar terminaría afirmando el prejuicio de la mujer objeto. De eso trataba "El enano erótico", nombre de la historieta que publicaba Alfredo Marcos en el diario de corte sensacionalista.

Por otra parte, El Comercio había renunciado, hasta ese momento, a condenar el autogolpe. En sus páginas interiores, en secciones y columnas, la información fluía copiosamente, casi buscando eliminar esa delgada línea que dividía los hechos consumados el 5 de abril de 1992, de los sucesos de la víspera. La propia portada de El Comercio, del 6 de abril de 1992, convirtió la hazaña golpista en algo anecdótico y sensacional. ${ }^{3}$

Pero la caricatura fue más allá. Libre de toda censura y sin mayores reparos, elaboró un mensaje celebrando indirectamente el autogolpe. Saludaba el ingreso de la policía a los penales, sin importarle su inconstitucionalidad. ${ }^{4}$ El caos, los abusos, la indisciplina, la corrupción y, sobre todo, el "adoctrinamiento de los delincuentes terroristas", justificaban, para la caricatura de $E l$ Comercio, el ingreso de la policía a las prisiones peruanas. Su administración, a cargo del Instituto Nacional Penitenciario (INPE), debió agravar la situación carcelaria. Pero, en realidad, lo que preocupaba al régimen y a sus eventuales aliados, era el tema de Sendero Luminoso.

3 El lacónico titular de El Comercio, al día siguiente del golpe de Estado, fue el siguiente: "En sorpresivo mensaje al país, Fujimori dispuso anoche disolución del Congreso" (TvpeNoticias, 5 de abril de 2018; Infante 2007).

4 El Código de Ejecución Penal, en su artículo 113, prescribe que la seguridad de los establecimientos penitenciarios y dependencias conexas está a cargo del personal penitenciario de seguridad. Excepcionalmente, la seguridad exterior de estos establecimientos podría estar a cargo del Ministerio del Interior, siempre y cuando haya un requerimiento del INPE. 


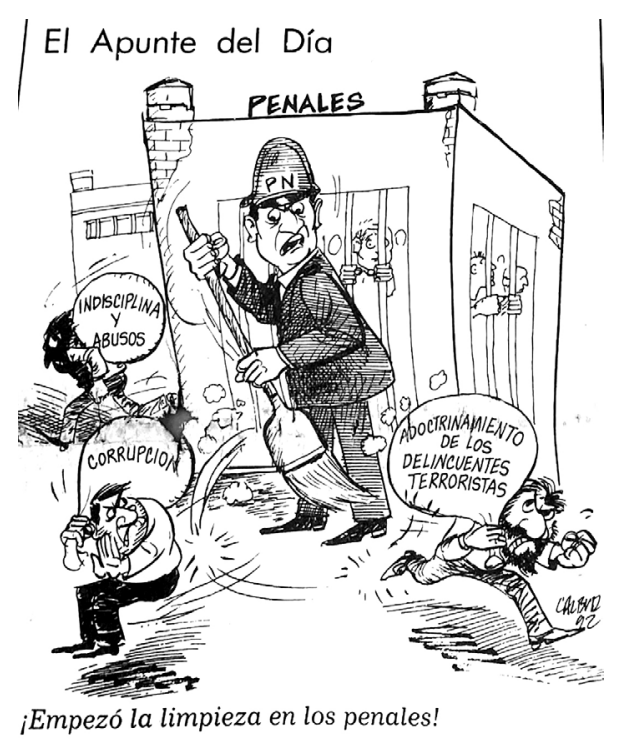

Figura 10. Lámina de "Apunte del Día”. Diario El Comercio, 9 de abril de 1992

El 6 de abril de 1992, el autodenominado Gobierno de Emergencia y Reconstrucción Nacional, emitió el Decreto Ley N ${ }^{\circ} 25421$, por el cual declaraba en reorganización al INPE y encargó al Ministerio del Interior a través de la Policía Nacional la administración y control de los establecimientos penitenciarios.

La caricatura se refería a esto. Terminada la era del INPE, el control y el restablecimiento del orden pasarían a las manos de la policía nacional. Pero, el mensaje trascendía este simple anhelo oficial. Dejaba en claro que, solo, la fuerza era capaz de recuperar el equilibrio. Y, si el orden constitucional no podía hacerlo, lo haría una dictadura. No había diferencias. El fin justificaba los medios. El golpe de Estado resolvería el problema.

Aislado ante la comunidad internacional, Fujimori creyó estar compensando el rechazo de aquellas latitudes, con el baño de popularidad que venía recibiendo tras la disolución del Congreso y de otros organismos que resguardaban el orden constitucional. Martín Tanaka y Jane Marcus-Delgado (2001, 20) señalan que los índices de aprobación de Fujimori, con el golpe de Estado, se ubicaban en un rango de 70 y 80 \%. Es más, "la aprobación de la gestión presidencial entre 1992 y 1996, prácticamente no bajó del 60 \% y, a lo largo de 1995, estuvo casi siempre por encima del 70 \%”" (Tanaka y Macurs-Delgado 2001, 78), con un respaldo importante en sectores populares. 
Aunque los datos proporcionados por las encuestadoras no siempre reflejaban fielmente la realidad, las preguntas que, generalmente, solían hacer, reducían opciones o inducían en uno u otro sentido a la opinión pública, lo cual llevaba a descubir cierto subjetivismo en los resultados de las encuestas.

Nuestra intención por examinar el dato que representa la construcción social de la caricatura de Alfredo Marcos, quien dibujaba a Fujimori, elevándolo deliberadamente a la categoría de mesías (véase figura 11), rodeado de una multitud de fieles, pero encerrado en los límites de una isla, algo que podría entenderse como el pequeño espacio de tierra firme; nos traslada a un extraordinario simbolismo, que nos proponemos analizar seguidamente.

¿Era Fujimori el mesías que tanto esperaba el país?

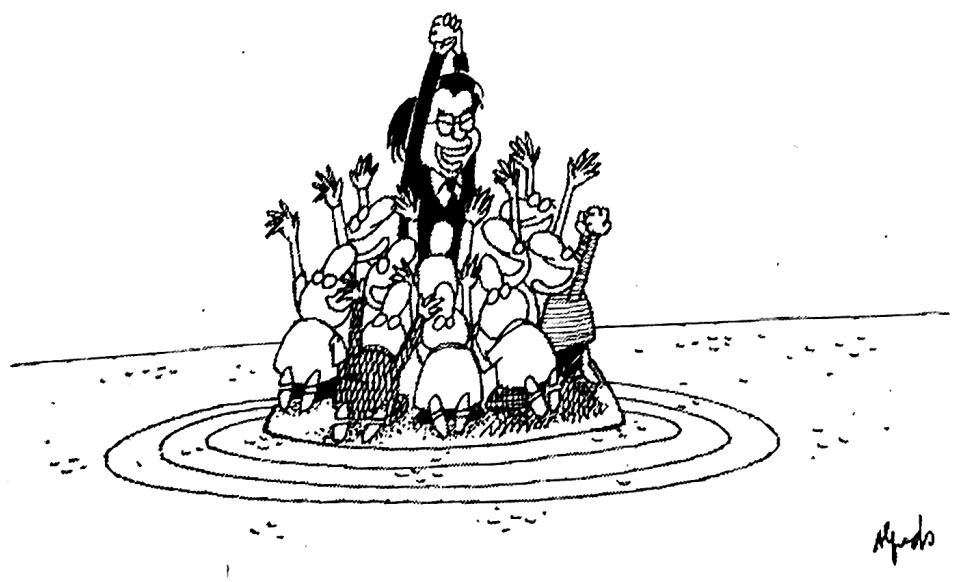

Figura 11. Lámina de Alfredo Marcos. Diario La República, 10 de abril de 1992

En una sociedad dominada por fuertes prejuicios sociales, culturales y por una larga tradición de paternalismo (Obregón 2019), la figura del mesías o del "inka rey", parafraseando a Alberto Flores Galindo, alcaza un significado excepcional.

Fujimori buscaba encarnar esa imagen salvadora, buscaba verse como el "líder predestinado e iluminado; el que de manera providencial salvó al Perú de la hiperinflación, lo pacificó e impuso el orden mediante el uso implacable del poder" (Nizama 2009, 227).

Esta meta-mirada, tan propia de un megalómano, había sido advertida por Alfredo Marcos. Su caricatura pinta de cuerpo entero a Fujimori, lo descubre en una de sus más bajas pasiones, pero, al mismo tiempo, se propone destruir- 
lo. La isla, un espacio de limitadas fronteras, posee múltiples interpretaciones. No es la isla de elección, de ciencia y de paz, que se convierte en el último reducto frente a la ignorancia y a la agitación del mundo profano (Chevalier 1986, 596); la isla de Fujimori es la diminuta porción de tierra, frente a la inmensidad del cosmos. Un golpe de Estado que, a los ojos de una sociedad con fuerte inicidencia pragmática, dominada por sus propios traumas y por la brutal ofensiva de una patología social que la carcome; descubre el calor de efímeros aplausos que, tarde o temprano, se vuelven en contra suya y en contra de su codicia.

Esta es la isla, convertida en su breve refugio, rodeada de la inmensidad del mar o, más bien, de ambivalencia e incertidumbre, "de la duda, de la indecisión y que puede concluirse bien o mal” (Chevalier 1986, 689).

Carlos Roose Silva, conocido también como Crose, como lo dijimos, estaba a cargo de los dibujos del diario Ojo. Sus viñetas seguían la misma racionalidad del humor gráfico capitalino. Colaboraba con un periódico que compartió antes, durante y después del golpe, el ideario fujimorista, no porque tenía simpatías gratuitas, sino, porque apostaba por el proyecto neoliberal y por las ventajas que debía brindarle un mercado donde la participación del Estado sería casi nula.

La imagen de Fujimori en la caricatura, no había cambiado. Seguía siendo el mismo personaje de las ediciones anteriores a la fecha del golpe. Esto decía mucho. Sus gestos eran los mismos, no hubo cambio alguno, no era el rabioso y beligerante hombre que había capturado el poder utilizando la fuerza militar. Seguía siendo el diminuto hombre de ojos alineados, de sonrisa etérea y carismática, vestido con un kimono, el atuendo oriental que caracterizaba al guerrero, al hombre honorable y luchador, a esa especie de samurai de la edad medieval, que exhibía el cinturón negro, como garantía de su experiencia.

De esto se trataba el humor gráfico de los años del golpe, de ilustrar a un público nativo, desinformado, desafecto y escasamente consciente de la dinámica neoliberal. Fujimori actuaba de intérprete y la caricatura le era funcional. El mensaje ulterior, en cambio, estaba dirigido a la opinión pública internacional. Su compromiso en favor del restablecimiento del orden democrático pasaba por demostrar el respaldo a su gobierno desde sectores sociales menos favorecidos.

Su demagógico discurso inclusivo y populista se caería poco tiempo después, al descubrirse, no solo la gigantesca corrupción que se organizó desde el interior de su gobierno, sino, el grave daño que le hizo a la economía nacional, 
al privilegiar el capital transnacional y desaparecer la producción nacional, eliminando aranceles, privatizando la mayoría de empresas nacionales estratégicas y concesionando cielo, tierra y mar a precios ofensivos para el interés del país. La magnitud del daño que representó la implementación del neoliberalismo en suelo peruano solo se conocería dos décadas más tarde (Durand 2004, 2016; Honorio 2009).

La ironía aparecía en toda su plenitud. Miguel Ángel puso a prueba la capacidad proyectiva de la caricatura (ver figura 12). Veinte años despúes, la realidad le daría la razón. Keiko Fujimori, hija de Alberto Fujimori, llegó a postular en dos oportunidades (2011 y 2016) al cargo más alto del Estado peruano, con resultados desfavorables. Se proclamaba sucesora de su padre, aunque su intención, además de perennizar el apellido y la tradición, fue defender las reformas políticas y económicas aplicadas durante la década del noventa, bajo una inspiración autoritaria.

Lo cierto es que Fujimori siempre tuvo en mente poner a sus hijos en la misma línea de descendencia política emulando la tradición monárquica de la sucesión dinástica.

\section{MIGUEL ANGEL}

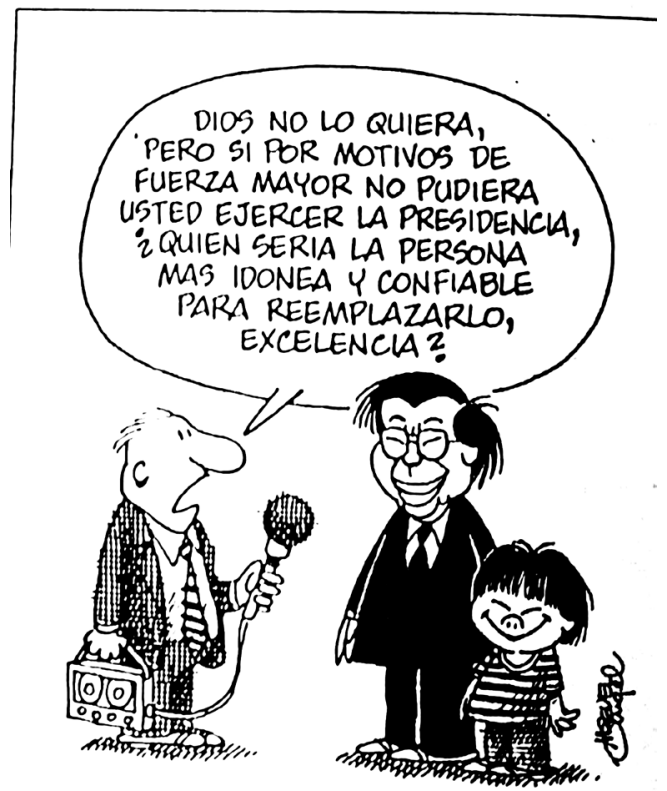

Figura 12. Lámina Miguel Ángel. Diario Expreso, 17 de abril de 1992 
Parecía contradictoria la posición de Expreso si, como sabemos, actualmente, es uno de los mejores aliados del fujimorismo; pero, la línea trasada por el régimen que apuntaba a una reforma audaz de la política económica, una especie de huida hacia adelante, con la implementación del neoliberalismo, había despertado naturales temores en los sectores más conservadores. El Comercio y Expreso, de propietarios tradicionalmente conservadores, actuaron con mucha cautela frente al autogolpe. Eran sus inversiones y la de los intereses de grandes capitales nativos y foráneos, los que estaban en juego. En el caso de Expreso, la prudencia era mayor. Manuel Ulloa, propietario del medio, Manuel D'Ornellas, Patricio Rickets y otros conocidos columnistas de este impreso, parecían no estar dispuestos a someterse a otro ensayo en la economía. Dos décadas antes, fueron testigos de excepción de la experiencia militar que puso en riesgo el patrimonio de la familia Ulloa y de la oligarquía peruana.

Era comprensible, entonces, su temor ante un giro de la economía tras el golpe de Estado. Si bien, desde agosto de 1990, fecha en que un ajuste estructural de la economía controló la hiperinflación, la confianza de Expreso en el régimen se restableció a medias. El autogolpe de abril de 1992, volvió a despertar los miedos. La garantía para que el mercado siguiera un rumbo seguro, volvería a depender de la maquinaria política, representada por el Estado. La dictadura era eso: poner al Estado al frente de la dinámica social, política y económica. Esto parecía estar lejos de la idea de convertirlo en un Estado Neoliberal (Huerta, 2005).

La posición bastante reservada de los organismos cooperantes en el extranjero no garantizaba un buen síntoma del posible futuro de la economía, no solo por las inversiones, por la inyección del capital o por los préstamos; era, también, por la estabilidad política y jurídica, que espantarían cualquier interés de inversión extranjera.

La economía no tendría otro destino que el precipicio o, mejor, el abismo que, para el simbolismo clásico, significa un espacio "sin fondo" y designa el mundo de las profundidades, que guarda el sentido general del infierno (Chevalier 1986, 52). Y aunque no se necesita más que apelar al sentido común para entender el destino apocalítpico, la razón nos devuelve a la necesidad de explicar esas conexiones internas que fluyen entre lo subjetivo y lo objetivo, entre lo simbólico y lo real. Pero, lo único real fue el temor de la oligarquía por el rumbo que, a su juicio, seguiría la economía. Sí, era temor, una emoción que camina por esa esfera llamada subjetividad humana y que forma parte de la realidad social. 


\section{Síntesis}

¿La caricatura es problética? Mario Trevi señala que hay dos tipos de símbolos que trascienden el espacio simbólico. Uno, llamado generador y otro proyectivo o problético, que nos remite al problolé o al proyecto (Trevi 1996, 6). Es decir, este tipo de símbolo guarda relación con su capacidad de proyectarse en el tiempo (Infante 2010, 41), de verse en el futuro como una estructura simbólica sin perder su capacidad maleable. Si este es el caso, la caricatura, un artefacto cultural de esencia social, organizado por una dosis potente de simbolismo, encuentra esta característica, se convierte en una corporación simbólica problética. No, porque adivine un hecho que fue motivo de humor en algún momento, sino, porque adquiere más vitalidad, en la medida en que trasciende el tiempo y el espacio, en la medida en que su valor se refleje históricamente, tenga significado y forme parte de nuevas construcciones simbólicas.

La caricatura sigue siendo funcional y seguirá siéndolo. Como toda herramienta de la comunicación y de la interacción social, obtendrá esa condición (instrumental) solo si sus operadores, los humoristas, le conceden esa función. La caricatura crítica, de la que hablamos en otros ensayos y artículos (Infante 2008, 2010, 2015, 2020), en cambio, si bien no se aparta de su funcionalidad, algo que termina siendo inherente, se somete al espíritu de un tipo de caricatura más completo, consistente, trascendente en el tiempo y dinámico. El otro es vacío, fútil, acaso, intrascendente.

La fluidez del contexto político que representó el golpe de Estado puso en tensión a la caricatura, como a las otras formas de expresión. En el caso de la caricatura, de aquella que compartió la racionalidad oficial, siguió el ritmo de un discurso que pretendió legitimar la ruptura del orden constitucional. De este modo, el discurso se volvió permeable a los imaginarios y, de ahí, al sentido común (Infante 2010). En el estudio que hicimos sobre el humor gráfico, descubrimos esta conexión: humor, imaginario y sentido común, una secuencia que alimenta y se retroalimenta, como todo proceso comunicativo, que ordena y reordena el discurso.

Si la economía movió el interés político, como sugiere González de Olarte (2007), toda la esfera de la cultura empalmó con este ritmo. La caricatura, como dijimos, producto cultural de esencia social, no pudo estar fuera de esta dinámica, siguió el curso de aquel proceso, un proceso que no fue uniforme. Como todo fenómeno dialéctico, la caricatura política descubrió su carácter maleable. 


\section{Referencias bibliográficas}

Ames, A. 2017. La pobreza en los noventa. Diario Perú 21, 31 de diciembre. https:// peru21.pe/opinion/pobreza-noventa-390239-noticia/?ref=p21r.

Adrianzén, A. 2011. La izquierda derrotada. En Adrianzén, A. (Ed.). Apogeo y crisis de la izquierda peruana. Hablan sus protagonistas, 45-61. Lima: IDEA Internacional.

Bailón, J. 2004. La chicha no muere ni se destruye, solo se transforma. Iconos, revista de Ciencias Sociales, 18, 53-62. https://www.redalyc.org/pdf/509/50901807.pdf.

Bourdieu, P. 1990. Sociología y cultura. Ciudad de México: Editorial Grijalbo.

Burt, J.-M. 2011. Violencia y autoritarismo en el Perú: bajo la sombra de Sendero y la dictadura de Fujimori. Lima: IEP. https://repositorio.iep.org.pe/bitstream/IEP/613/2/ ideologiaypolitica31.pdf.

Cappellini, M. 2004. La prensa “chicha" en Perú. Revista latinoamericana de comunicación Chasqui, 88, 32-37. https:/www.redalyc.org/pdf/160/16008806.pdf.

Chevalier, J. 1986. Diccionario de los símbolos. Barcelona: Editorial Herder.

CVR. 2004. Informe final (t. II, III y V). Lima: CVR.

Cotler, J. y Grompone, R. 2000. El fujimorismo. Ascenso y caída de un régimen autoritario. Lima: IEP.

Durand, F. 2004. Neoliberalismo, empresarios y estado. Debates en Sociología, 29, 40-84. http://revistas.pucp.edu.pe/index.php/debatesensociologia/article/view/7021.

Durand, F. 2016. Cuando el poder extractivo captura el estado. Lobbies. Puertas giratorias y paquetazo ambiental en Perú. Lima: Oxfam. https://peru.oxfam.org/sites/peru. oxfam.org/files/file_attachments/capturadurand\%20VF.pdf.

Flores Galindo, A. 1999. La tradición autoritaria: Violencia y democracia en el Perú. Lima: SUR. Casa de Estudios del Socialismo-APRODEH.

Gonzales, O. 1999. La crisis de los partidos peruanos. Apuntes para una lectura socio- histórica. Espacio abierto, 8 (3), 305-324. http://www.redalyc.org/pdf/122/12208302. pdf.

Gonzales, O. 2011. La izquierda peruana: una estructura ausente. En Adrianzén, A. (Ed.) Apogeo y crisis de la izquierda peruana. Hablan sus protagonistas, 15-45. Lima: IDEA Internacional.

Gonzales de Olarte, E. 2007. La economía política peruana de la era neoliberal 19902006. Center for Integrated Area Studies (CIAS), 11-37. https://repository.kulib. kyoto-u.ac.jp/dspace/bitstream/2433/228393/1/ciasdp02_11.pdf.

Gonzales de Olarte, E. y Samamé, L. 1991. El péndulo peruano. Políticas económicas, gobernabilidad y subdesarrollo, 1963-1990. Lima: IEP. 
Grompone, R. 2000. Al día siguiente. El fujimorismo como proyecto inconcluso de transformación política y social. En Cotler, J. y Grompone, R. El fujimorismo: ascenso y caída de un régimen autoritario. Lima: IEP.

Honorio,J.2009.Neoliberalismoygenocidioenelrégimenfujimorista.RevistaHAOL, 19,6575. https://www.academia.edu/23681490/NEOLIBERALISMO_Y_GENOCIDIO.

Huerta, M. 2005. El neoliberalismo y la conformación del Estado subsidiario. Política y cultura, 24, 121-150. https://www.redalyc.org/pdf/267/26702406.pdf.

Infante, C. 2007. Canto Grande y las Dos Colinas. Del exterminio de los pueblos al exterminio de comunistas en el Penal Castro Castro. Mayo 1992. Lima: Manoalzada.

Infante, C. 2008a. Poder y humor gráfico durante el período de crisis del régimen de Alberto Fujimori, 1996-2000 (tesis doctoral). Lima: Universidad Nacional Mayor de San Marcos.

Infante, C. 2008b. Poder, tensión y caricatura. Una aproximación a la teoría del humor. Revista Dialogía, 1 (3), 245-271. https://www.journals.uio.no/index.php/Dialogia/ article/view/4064.

Infante, C. 2010. Poder, tensión y caricatura durante el periodo final del régimen fujimorista. Lima: Fondo Editorial de la UNMSM, Manoalzada.

Infante, C. 2015. El humor gráfico en el Perú: inicio, desarrollo y consolidación de la caricatura. Pacarina del Sur, 6 (23). http://www.pacarinadelsur.com/editorial/51dossiers/dossier-15/1119-el-humor-grafico-en-el-peru-inicio-desarrollo-y-consolidacion-de-la-caricatura.

Infante, C. 2019. Sentido común, discurso antineoliberal y conciencia política en la sociedad ayacuchana. Perú, 2010. Revista Ciencias Sociales, 1 (2), 125-144.

Infante, C. 2020. Flujos y reflujos de la caricatura política peruana durante el conflicto armado interno. Perú 1980-1990. Pacarina del Sur (Revista en Línea), 11 (42). http:// pacarinadelsur.com/home/pielago-de-imagenes/1849-flujos-y-reflujos-de-la-caricatura-durante-el-conflicto-armado-interno-en-peru-1980-1990.

INEI. 2016. Comportamiento de la economía peruana 1950-2015. Lima: INEI. https:// www.inei.gob.pe/media/MenuRecursivo/publicaciones_digitales/Est/Lib1359/ cap01.pdf.

Lora Cam, J. 2001. Perú: La débil reaparición de los sujetos bajo la subalternidad electoral. Bajo el Volcán, 2 (3), 99-120. Puebla: Benemérita Universidad Autónoma de Puebla. https://www.redalyc.org/pdf/286/28600306.pdf.

Marcus-Delgado, J. y Tanaka, M. 2001. Lecciones del final del fujimorismo. La legitimidad presidencial y la acción política. Lima: IEP.

Matos Mar, J. 1986. Desborde popular y crisis del Estado. Lima: IEP. 
Nizama, M. 2009. El síndrome de Fujimori. Revista IIPSI, 12 (1), 215-237. https://www. researchgate.net/publication/43106018_El_sindrome_de_Fujimori.

Obregón, W. 2019. El porvenir de las razas: el racialismo en el Perú entre los siglos XIX y XX. Revista Análisis, 51 (94). https://www.redalyc.org/jatsRepo/5155/515559181003/html/index.html\#fn21.

Ortiz de Zárate, R. 2016. Alberto Fujimori. Perú. Barcelona Centre For International Affairs. https://www.cidob.org/biografias_lideres_politicos/america_del_sur/peru/ alberto_fujimori\#8

Palmer, S. 1992. Perú 1992: la sorpresa de abril de Fujimori. Estudios Internacionales, 25 (99), 378-384. https://core.ac.uk/download/pdf/46534318.pdf.

Tanaka, M. 1998. Los espejismos de la democracia. El colapso del sistema de partidos en el Perú, 1980-1995, en perspectiva comparada. Lima: IEP.

Tanaka, M. y Marcus-Delgado, J. 2001. ¿Crónica de una muerte anunciada? Determinismo, voluntarismo, actores y poderes estructurales en el Perú, 1980-2000. En Tanaka, M. Lecciones del final del fujimorismo. La legitimidad presidencial y la acción política, Lima: IEP.

Trevi, M. 1996. Metáforas del símbolo. Barcelona: Anthropos.

Villari, C., Menacho, L. 2017. La situación lingüística actual en Áncash como reflejo de la historia de la política lingüística del Perú. Indiana, 34 (1), 129-147. https://www. redalyc.org/jatsRepo/2470/247053511006/247053511006.pdf.

Zapata, J. y Chávez, M. 2017. Las corrientes ortodoxa y heterodoxa del desarrollo: algunas nociones conceptuales. Opera, 22. https://www.redalyc.org/jatsRepo/675/67557558009/html/index.html. 